\title{
Studi Kelayakan Pembangunan Flyover Di Simpang Gedangan Sidoarjo Di Tinjau Dari Segi Lalu Lintas Dan Ekonomi Jalan Raya
}

\author{
Nanang Firmansyah dan Istiar \\ Jurusan Teknik Sipil, Fakultas Teknik Sipil dan Perencanaan, Institut Teknologi Sepuluh Nopember (ITS) \\ Jl. Arief Rahman Hakim, Surabaya 60111 Indonesia \\ e-mail: istiar@yahoo.com
}

\begin{abstract}
Abstrak - Kemacetan lalu lintas adalah masalah umum di Sidoarjo, terutama pada persimpangan Gedangan yang merupakan kawasan industri. Penyebabnya adalah lalu lintas yang padat, terutama pada jam puncak dan adanya perlintasan kereta api di Jalan Sedati. Untuk mengatasi masalah ini, perlu dibangun jembatan layang (flyover) di persimpangan Gedangan. Sebelum jembatan layang (flyover) dibangun, perlu meninjau studi kelayakan terhadap kinerja lalu lintas dan jalan raya ekonomi.

Studi kelayakan yang didasarkan pada kinerja lalu lintas, adalah untuk membandingkan derajat kejenuhan jalan sebelum dan sesudah jembatan dibangun. Sementara studi kelayakan yang didasarkan pada jalan raya ekonomi, ditinjau dari parameter BCR (rasio nilai sekarang manfaat dengan biaya) dan NPV (selisih nilai sekarang antara manfaat biaya) dari konstruksi flyover Gedangan.

Metode yang digunakan untuk analisis kinerja lalu lintas, Manual Kapasitas Jalan Indonesia (MKJI). Dan untuk metode yang digunakan kendaraan analisis biaya operasi, metode Jasa Marga dan metode Clarkson H. Oglesby \& R. Gary Hicks.

Dengan pembangunan jembatan, derajat kejenuhan berkurang dari 1,4 ke 0,7 untuk arah Surabaya - Sidoarjo, dan sementara derajat kejenuhan dalam arah yang berlawanan berkurang dari 1,39 ke 0,7 . Jadi pembangunan flyover tersebut layak, ditinjau dari kinerja lalu lintas. Sedangkan perhitungan analisis kelayakan ekonomi, diperoleh nilai BCR adalah 24 dan Net Present Value adalah 2.140.715.260.868. Sehingga, pembangunan flyover Gedangan persimpangan Sidoarjo adalah layak secara ekonomis.
\end{abstract}

Kata kunci: Fly Over, Kemacetan, Studi Kelayakan, Persimpangan

\section{PENDAHULUAN}

$\mathrm{K}$ abupaten Sidoarjo merupakan kabupaten terkecil dan terpadat penduduknya di Jawa Timur, dengan luas wilayah 63.438,534 ha atau 634,39 $\mathrm{km}^{2}$ (pariwisata.sidoarjokab.go.id). Sebagai wilayah bagian dari SWP (Satuan Wilayah Pembangunan) gerbangkertosusila, Sidoarjo telah mendapatkan efek dari kota Surabaya sebagai pusat pertumbuhan. Sektor perindustrian dan perdangangan berperan besar dalam menunjang perekonomian di kota Sidoarjo. Untuk melaksanakan semua itu diperlukan sarana dan prasarana penunjang, dalam hal ini adalah jalur transportasi darat. Agar pendistribusian barang dapat berjalan lancar maka jalur transportasi harus diperhatikan dengan baik, sebab salah satu hal yang menghambat pendistribusian barang adalah jika terjadi kemacetan.

Kemacetan merupakan masalah sering terjadi di Sidoarjo terutama di perempatan Gedangan yang terletak di jalan Ahmad Yani, Kecamatan Gedangan. Perempatan Gedangan merupakan perpotongan antara 4 ruas jalan yaitu sebelah timur berbatasan dengan Jalan Jenggolo (Sedati), sebelah barat Jalan Sukodono, sebelah utara Jalan Ahmad Yani (dari Surabaya), dan sebelah selatan Jalan Raya Gedangan (ke arah Sidoarjo). Wilayah ini cukup padat lalu lintas karena wilayah ini terkenal sebagai wilayah industri terutama pada jam sibuk pukul 06.00 - 09.00 dan 16.00 19.00. Wilayah ini menjadi macet karena tidak sebandingnya volume kendaraan dan volume jalan. Jalur dari utara, selatan, memiliki lebar jalan masing masing 7 meter sedangkan wilayah barat dan timur memiliki lebar jalan 6 meter. Ditambah lagi dengan adanya perlintasan sebidang kereta api di Jalan Jenggolo (Sedati) ini dan jalan ini merupakan jalur utama truk-truk yang mau ke pergudangan yang ada di jalan sukodono. Dilihat juga dari pengaturan traffic light, di perempatan Gedangan ini juga menimbulkan masalah, untuk jalur utara dan selatan, lampu merah menyala selama 37 detik dan lampu hijau sampai 98 detik. Itu berbeda dengan jalur dari timur yang lampu hijaunya menyala selama 20 detik saja, sedangkan lampu merah menyala sampai 108 detik (Arjaka, 2014). Jika ditinjau dari sisi ekonomi, tundaan kendaraan yang terjadi akibat kereta api lewat dan traffic light merupakan biaya (cost) lebih yang harus dibayar pengguna kendaraan akibat mengalami tundaan di simpang. Hal ini jika dihitung dalam waktu yang panjang, ditambah dengan kecenderungan bertambahnya jumlah kendaraan yang ada, maka biaya yang harus dikeluarkan penggunaan kendaraan ini akan semakin besar (Yasfina, 1999)

Untuk mengatasi permasalahan yang terjadi pada perempatan tersebut ada beberapa solusi yang telah diterapkan antara lain pelebaran jalan dan pembaruan sistem traffic light. Akan tetapi kedua alternatif tersebut masih belum bisa mengatasi kemacetan, karena volume kendaraan yang memang cukup besar dan mengakibatkan tundaan di masing masing ruas jalan, khususnya pada ruas dari arah Ahmad Yani ke ruas Jalan Raya Gedangan. Sehingga diperlukan alternatife antara lain yaitu flyover. Karena flyover di anggap tepat menjadi solusi mengatasi permasalahan simpang gedangan sidoarjo, akan tetapi perlu 
dilakukan studi terkait pembangunan fly over pada simpang gedangan sidoarjo.

Oleh karena itu dalam penelitian ini di usulkan penelitian yang berjudul Studi Kelayakan Pembangunan Flyover di Simpang Gedangan Sidoarjo di Tinjau dari Segi Lalu Lintas dan Ekonomi Jalan Raya.

A

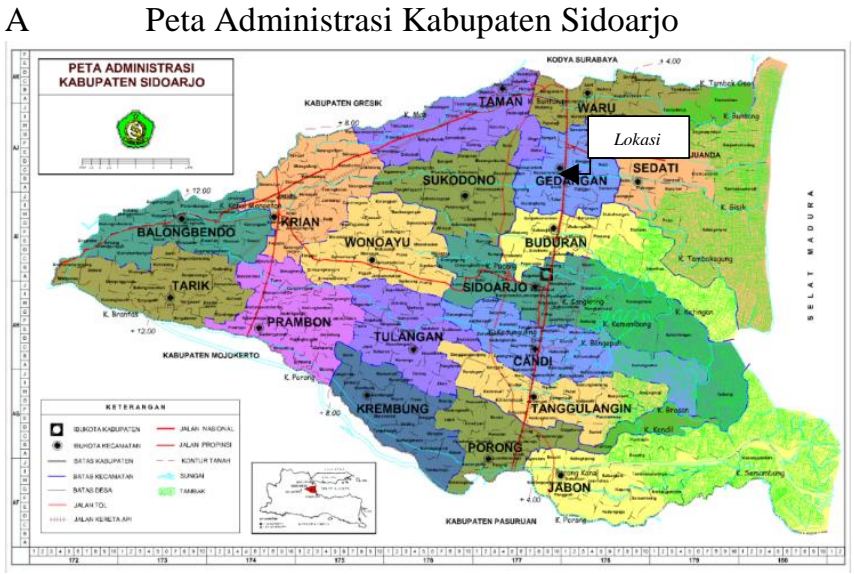

Gambar 1. Peta Kabupaten Sidoarjo

B Lokasi Perencanaan Pembangunan Flyover Gedangan

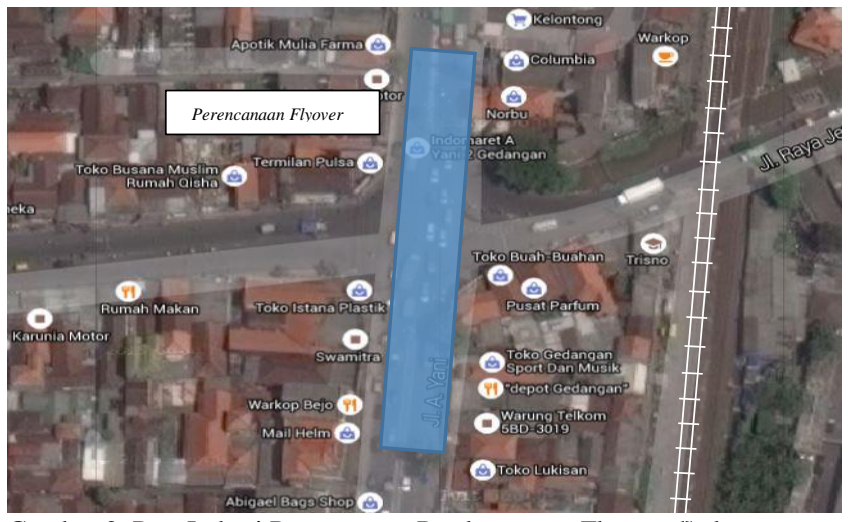

Gambar 2. Peta Lokasi Perencanaan Pembangunan Flyover Gedangan

\section{TINJAUAN PUSTAKA}

\section{A. Persimpangan}

Persimpangan adalah simpul pada jaringan jalan dimana jalan-jalan bertemu dan lintasan kendaraan berpotongan. Lalu lintas pada masing-masing kaki persimpangan menggunakan ruang jalan pada persimpangan secara bersama-sama dengan lalu lintas lainnya. [6]

Persimpangan dibedakan menjadi 2 yaitu persimpangan sebidang dan persimpangan tidak sebidang

\section{B. Karakteristik Jalan Perkotaan}

Untuk mengetahui kapasitas jalan dari suatu kota yang akan dibebani lalu lintas diperlukan data tipe jalan, lebar efektif, pemisah arah, lebar bahu efektif, kelas hambatan samping dan penyesuaian ukuran kota yang didapat dari pertumbuhan penduduk disuatu wilayah yang kita tinjau [3].

\section{Biaya Operasional Kendaraan}

Biaya operasional kendaraan adalah biaya yang digunakan kendaraan beroperasi dari suatu tempat menuju ke tempat lain ( aktifitas transportasi ). Metode yang digunakan untuk menghitung biaya operasional kendaraan dalam penelitian ini, adalah dengan menggunakan dua metode yaitu, Metode Jasa Marga dan Metode Clarkson H. Oglesby \& R. Gary Hicks. Metode JasaMarga digunakan untuk menghitung BOK Flyover dan di kombinasikan dengan metode N.D. LEA \& Associates Report 1975untuk kendaraan bermotor. Sedangkan metode Clarkson $\mathrm{H}$. Oglesby \& R. Gary Hicks digunakan untuk menghitung BOK simpang pada perempatan Eksisting [1] Gedangan Sidoarjo.

\section{Nilai Waktu}

Nilai waktu yang dihitung berdasarkan formula PT. Jasa Marga untuk fly over atas.[5]

Nilai Waktu $=\operatorname{Max}\{$ KxNilai Waktu Dasar $)$; Nilai Waktu Minimum $\}$

\section{E. Analisis Ekonomi}

\section{a. Benefit Cost Ratio (BCR)}

Perhitungan dilakukan dengan cara membandingkan semua manfaat dengan (benefit) dengan biaya (cost) total yang dibutuhkan, setelah dikonfersikan kedalam nilai uang sekarang (present value). Jika nilai $\mathrm{BCR}<1$ artinya manfaat yang diterima lebih kecil dari biaya yang dikeluarkan, $\mathrm{BCR}=1$ berarti besarnya manfaat seimbang dengan biaya yang dikeluarkan sedangkan BCR $>1$ berarti manfaat yang diterima lebih besar daripada biaya yang dikeluarkan

\section{b. Net Present Value (NPV)}

Metode Net Present Value (NPV) dilakukan dengan cara mengurangi semua manfaat biaya (cost) total yang dibutuhkan setelah dikonversikan kedalam nilai uang sekarang. Dari buku yang berjudul "Priciple of Engineering Economi $3^{\text {rd }}$ Edition" Karangan Grant Ireson Learnenworth dengan perumusan

$$
\mathrm{NPV}=\text { Benefit }- \text { Cost }
$$

Proyek dikatakan layak untuk dilaksanakan bila manfaat yang ditimbulkan proyek lebih besar dari biaya yang diperlukan untuk realisasi, dikatakan layak apabila NPV > 0 .

\section{METODOLOGI PENELITIAN}

Metodologi pada penulisan penelitian ini antara lain dapat dilihat pada penjelasan dibawah ini:

\section{A. Pengumpulan Data}

Dalam penyusunan penelitian ini dibutuhkan beberapa jenis data yang dibutuhkan,

- Geometrik jalan

Data ini dipakai untuk menghitung kapasitas jalan, diperoleh dari Sekolah Tinggi Transportasi Darat dalam bentuk gambar.

- Jumlah LHR

Data diperoleh dari melakukan survei traffic counting pada lokasi studi untuk mengetahui kepadatan volume lalu lintas pada simpang Gedangan Sidoarjo yang 
dilakukan oleh surveyor dari dinas perhubungan sidoarjo.

- Jumlah Penduduk

Yaitu data jumlah penduduk dalam beberapa tahun terakhir untuk meramalkan jumlah kendaraan. Yang didapat dari Badan Pusat Statistik Sidoarjo

- Komponen BOK

Komponen biaya operasional dapat diperoleh dari survei harga toko otomotif, harga bahan bakar, harga minyak pelumas, ban, harga mobil, dan upah montir.

- Rencana Tata Ruang Wilayah dan PDRB Daerah

Data ini dipakai untuk mengetahui rencana pembangunan yang ada di wilayah sekitar simpang Gedangan-Sidoarjo. Yang didapat dari Badan Perencanaan dan Pembangunan Daerah Sidoarjo

- Data Flyover dan Nilai Jual Objek Pajak

Data pembuatan flyover dipakai untuk membuat RAB flyover, data pembuatan flyover menggunakan referensi pembuatan flyover tandes oleh PT PP. Sedangkan untuk nilai Nilai Jual Objek Pajak yang nantinya digunakan untuk pembebasan lahan didapatkan dari Kantor Kepala Desa Daerah Keboan Sikep dan Kantor Kepala Desa Daerah Ketajen.

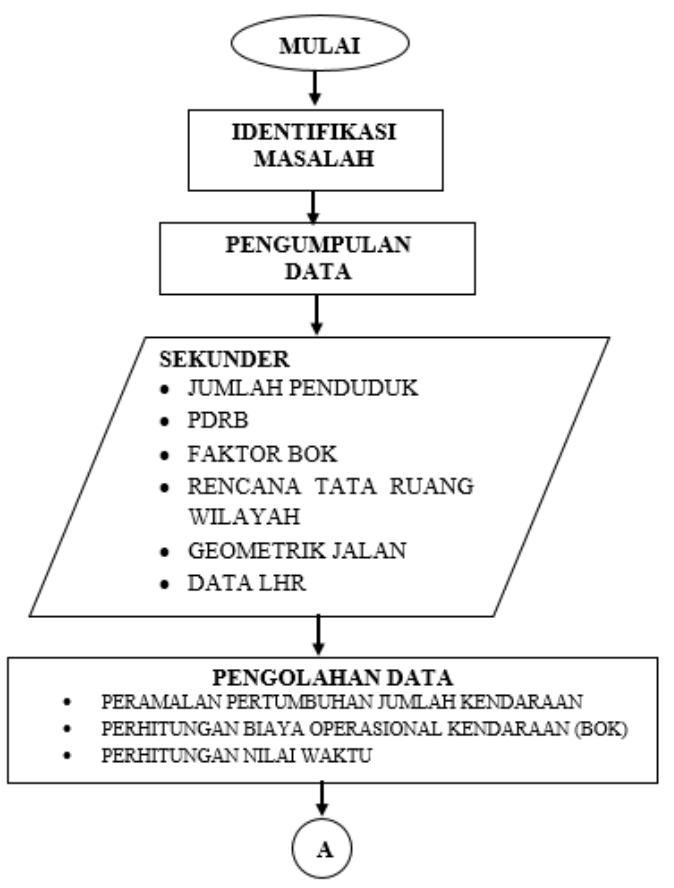

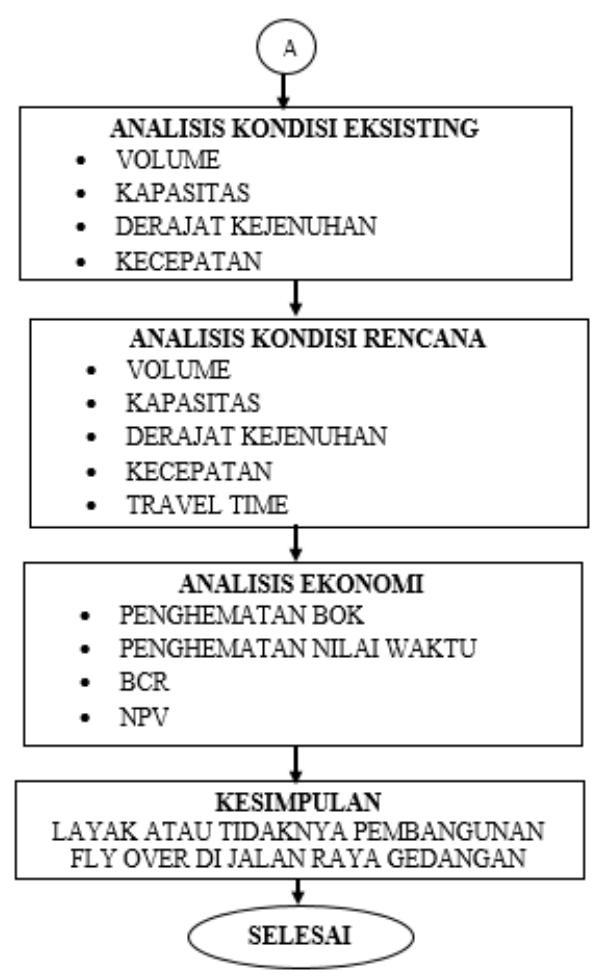

Gambar 3. Bagan Alir Penelitian

\section{DATA DAN ANALISIS}

\section{A. Uтит}

Analisa data dilakukan dengan cara menggabungkan data sekunder yang ada dari instansi-instansi terkait dengan data primer yang diperoleh melalui survey dilapangan.

\section{B. Analisis Kependudukan dan Perekonomian}

Agar dapat mengetahui volume lalu lintas yang akan melewati fly over ditahun yang akan datang, maka dilakukan peramalan pertumbuhan penduduk dan PDRB dengan metode selisih kuadrat terkecil dimana penyimpangan yang di usahakan sekecil mungkin agar didapat hasil mendekati keadaan sebenarnya. Contoh perhitungan dengan persamaan regresi linier adalah sebagai berikut:

$$
\begin{aligned}
a & =\frac{(n * \Sigma X Y-\Sigma X * \Sigma Y)}{\left(n * \Sigma X^{2}-(\Sigma X)^{2}\right)} \ldots \ldots \ldots \ldots \ldots \ldots \ldots \ldots \ldots \ldots \ldots \ldots \ldots \ldots \ldots \ldots \ldots \ldots \ldots \ldots \ldots \\
b & =\frac{(\Sigma Y-a * \Sigma X)}{(n)} \ldots \ldots \ldots \ldots \ldots \ldots \ldots \ldots \\
r & =\frac{(n * \Sigma X Y-\Sigma X * \Sigma Y)}{\sqrt{\left(n * \Sigma X^{2}(\Sigma X)^{2} * n * \Sigma Y^{2}-(\Sigma Y)^{2}\right)}} .
\end{aligned}
$$

Dengan menggunakan regresi linier maka akan didapatkan persamaan garis linier sebagai fungsional antara variabel - variabelnya. Sehingga dengan memasukkan nilai periode tahun data sebagai variabel $\mathrm{X}$ kedalam masing masing persamaan, maka akan didapat harga Y sebagai hasil estimasi masing - masing kriteria. 
Tabel 2.

Perkembangan Penduduk, PDRB, PDRB Perkapita Kota Sidoarjo Sampai Tahun Rencana

\begin{tabular}{|c|c|c|c|}
\hline \multirow{2}{*}{ Tahun } & Penduduk & PDRB & $\begin{array}{c}\text { PDRB } \\
\text { Perkapita }\end{array}$ \\
\hline & Jiwa & $\begin{array}{c}\text { Dalam Juta } \\
\text { Rupiah }\end{array}$ & $\begin{array}{c}\text { Juta } \\
\text { Rupiah/jiwa }\end{array}$ \\
\hline 2014 & $2,134,453$ & $79,337,251$ & $33,020,000$ \\
\hline 2015 & $2,176,204$ & $84,322,552$ & $35,200,000$ \\
\hline 2016 & $2,217,955$ & $89,307,852$ & $37,380,000$ \\
\hline 2017 & $2,259,705$ & $94,293,153$ & $39,560,000$ \\
\hline 2018 & $2,301,456$ & $99,278,454$ & $41,740,000$ \\
\hline 2019 & $2,343,207$ & $104,263,754$ & $43,920,000$ \\
\hline 2020 & $2,384,958$ & $109,249,055$ & $46,100,000$ \\
\hline 2021 & $2,426,709$ & $114,234,355$ & $48,280,000$ \\
\hline 2022 & $2,468,460$ & $119,219,656$ & $50,460,000$ \\
\hline 2023 & $2,510,211$ & $124,204,956$ & $52,640,000$ \\
\hline 2024 & $2,551,962$ & $129,190,257$ & $54,820,000$ \\
\hline 2025 & $2,593,713$ & $134,175,557$ & $57,000,000$ \\
\hline 2026 & $2,635,464$ & $139,160,858$ & $59,180,000$ \\
\hline 2027 & $2,677,214$ & $144,146,158$ & $61,360,000$ \\
\hline 2028 & $2,718,965$ & $149,131,459$ & $63,540,000$ \\
\hline 2029 & $2,760,716$ & $154,116,759$ & $65,720,000$ \\
\hline 2030 & $2,802,467$ & $159,102,060$ & $67,900,000$ \\
\hline 2031 & $2,844,218$ & $164,087,361$ & $70,080,000$ \\
\hline 2032 & $2,885,969$ & $169,072,661$ & $72,260,000$ \\
\hline 2033 & $2,927,720$ & $174,057,962$ & $74,440,000$ \\
\hline 2034 & $2,969,471$ & $179,043,262$ & $76,620,000$ \\
\hline 2035 & $3,011,222$ & $184,028,563$ & $78,800,000$ \\
\hline
\end{tabular}

\section{Faktor Pertumbuhan kendaraan}

Nilai faktor pertumbuhan lalu lintas diperoleh dengan membagi selisih angka hasil perkiraan tahun yang di tinjau dan angka tahun sebelumnya. Nilai faktor pertumbuhan inilah yang akan dijadiakan acuan untuk memperkirakan volume lalu lintas pada masa yang akan datang.

\section{Analisis Lalu Lintas}

Untuk mengetahui perilaku lalu lintas dan kepadatan pada suatu segmen jalan atau simpang pada kondisi lalu lintas [2] perempatan Gedangan Sidoarjo, digunakan DS sebagai acuan. Berikut, derajat kejenuhan dari arah Surabaya pada tahun pertama 2015

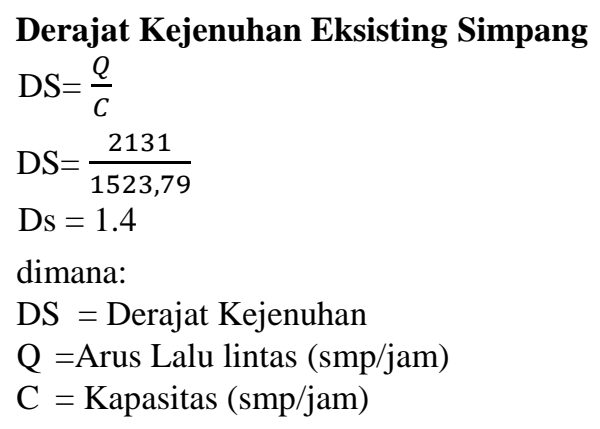

\section{Derajat Kejenuhan Rencana (fly over)}

$$
\begin{aligned}
& D S=\frac{Q}{C} \\
& \mathrm{DS}=\frac{2097}{2970} \\
& \mathrm{Ds}=0.7 \\
& \text { dimana: } \\
& \mathrm{DS}=\text { Derajat Kejenuhan } \\
& \mathrm{Q}=\text { Arus Lalu lintas }(\mathrm{smp} / \mathrm{jam}) \\
& \mathrm{C}=\text { Kapasitas }(\mathrm{smp} / \mathrm{jam})
\end{aligned}
$$

Dari perhitungan dapat dilihat, dengan adanya pembangunan fly over di perempatan Gedangan Sidoarjo nilai DS berkurang (DS < 1) maka pembangunan fly over di perempatan Gedangan Sidoarjo layak dari segi lalu lintas.

\section{V. ANALISIS KELAYAKAN}

\section{A. Perhitungan Biaya Operasional Kendaraan}

Metode yang digunakan untuk menghitung biaya operasional kendaraan dalam penelitian ini, adalah dengan menggunakan dua metode yaitu, Metode Clarkson $\mathrm{H}$. Oglesby \& R. Gary Hicks untuk simpang (eksisting) [8]dan untuk kondisi rencana ( fly over) menggunakan Metode Jasa Marga di kombinasikan dengan metode N.D. LEA \& Associates Report 1975 untuk kendaraan bermotornya[7] untuk (flyover atas) dan untuk simpang (bawah flyover) menggunakan Metode Clarkson H. Oglesby \& R. Gary Hicks digunakan untuk menghitung BOK. Nilai Waktu

Manfaat dari nilai waktu pada dasarnya merupakan penghematan waktu perjalanan yang dinilai secara ekonomis. Dan nilai waktu dikaitkan dengan besaran sejumlah uang yang dikeluarkan pengguna jalan untuk menghemat satu unit waktu perjalanan.

\section{Analisis Penghematan (Saving) User Cost}

Nilai penghematan (Saving) adalah selisih antara nilai saat kondisi (eksisting) sebelum project dibangun dan setelah project dibangun. Kondisi sebelum proyek dibangun merupakan perempatan sebidang bersinyal. Sedangkan kondisi (rencana) setelah ada proyek merupakan kondisi ketika flyover telah dibangun, jadi dapat disimpulkan.

Saving BOK $=$ Total BOK Before Project - Total BOK After Project

Saving Nilai Waktu = Total Nilai Waktu Before Project Total Nilai Waktu After Project

\section{Analisis Biaya Pembangunan Flyover}

Biaya investasi Flyover Gedangan didapat dari hasil analisa dan perhitungan dengan harga satuan bersumber dari harga satuan pekerjaan dan komponen (HSPK) 2015, yaitu untuk semua biaya investasinya adalah Rp $80,405,800,794$ untuk pembuatan flyover ditambah pembebasan lahan [4] sebesar Rp 3,811,500,000.

\section{E Analisa Kelayakan Ekonomi}

\section{1) Analisis Benefit Cost Ratio BCR.}

Tujuan analisa Benefit Cost Ratio (BCR) adalah untuk mengetahui apakah pembangunan Fly Over Gedangan Sidoarjo tersebut layak atau tidak dari segi ekonomi jalan raya. Pada perinsipnya analisa ini membandingkan antara besarnya investasi ( cost ) yang dikeluarkan dengan besarnya biaya penghematan (benefit) untuk pengguna jalan yang diperoleh dari pembangunan jalan tersebut. 
Analisa arus kas:

Biaya investasi pembangunan flyover + Biaya Pembebasan lahan

$=\operatorname{Rp~80,405,800,794+Rp~3,811,570,000~}$

$=\mathrm{Rp} 84,217,370,794$

Biaya Pemeliharaan

$=\operatorname{Rp} 595,763,659$ (tahun 2015) dan mengalami peningkatan sebesar $6,08 \%$ pertahun

Pendapatan pertahun $=$ Saving BOK + Saving Time Value Umur rencana $=20$ tahun

Tingkat suku bunga rata rata $=7.46$

Maka dari data diatas dapat dihitung nilai benefit present worth and cost present worth Dari hasil Benefit Cost Ratio ( BCR ) metode present worth dengan tingkat suku bunga rata rata $7.46 \%$ didapat hasil:

$\mathrm{BCR}=$ Total Present Worth Benefit $:$ Total Present Worth Cost

$=\operatorname{Rp} 2,234,764,617,708: \operatorname{Rp} 94,049,356,839$

$\mathrm{BCR}=24>1$ maka dapat disimpulkan Fly Over Gedangan dinyatakan layak secara ekonomi.

\section{2) Analisis Net Present Value (NPV)}

Dari hasil Net Present Value (NPV) Present Worth dengan tingkat suku bunga tingkat suku bunga rata rata $7.46 \%$ didapat hasil :

\section{NPV $=$ Total Present Worth Benefit - Total Present Worth Cost}$$
=\text { Rp 2,234,764,617,708 - Rp 94,049,356,839 }
$$

$\mathrm{NPV}=2,140,715,260,868>0$ maka dapat disimpulkan Fly Over Gedangan layak secara ekonomi.

\section{VI KESIMPULAN}

Berdasarkan hasil perhitungan dan analisa yang sudah dipaparkan pada BAB IV dan BAB V, maka didapatkan kesimpulan bahwa:

1. Berdasarkan hasil analisis dan perhitungan volume kendaraan yang melewati simpang Gedangan Sidoarjo, pada kondisi eksisting di tahun pertama (2015), menunjukkan nilai DS $=1,4$ untuk arah Surabaya Sidoarjo dan juga arah sebaliknya Sidoarjo - Surabaya dengan $\mathrm{DS}=1,39$. Maka disimpulkan kinerja jalan sudah sangat kritis dan tidak berfungsi dengan baik (DS>1), jika tidak ada penanganan khusus, maka kemacetan disimpang ini tiap tahun akan semakin parah. Jika dilihat dari hasil perhitungan pembangunan fly over, maka pembangunan fly over di perempatan Gedangan Sidoarjo layak dari segi lalu lintas, karena dengan adanya fly over nilai DS berkurang dari DS $=1,4$ untuk arah Surabaya - Sidoarjo menjadi DS=0,7 (DS<1) dan arah sebaliknya dari $\mathrm{DS}=1,39$ menjadi $\mathrm{DS}=0,7$ (DS<1).

2. Dengan dibangunnya flyover Gedangan Sidoarjo akan berefek baik pada perekonomian Kabupaten Sidoarjo. Jika dilihat dari nilai saving bok yang dihasilkan pada tahun pertama sebesar Rp 2,383,487,394 dan saving time value sebesar Rp 4,518,181,460 tentunya dengan adanya flyover ini akan menguntungkan, dan angka ini tentu akan terus meningkat seiring dengan bertambahnya waktu.

3. Dari Segi kelayakan ekonomi menunjukkan besarnya Nett Present Value sebesar Rp 2,140,715,260,868 (NPV> 0) serta Benefit Cost Ratio sebesar 24 (BCR > 1). Sehingga pembangunan Fly Over di perempatan Gedangan ini dinyatakan layak secara ekonomi

\section{UCAPAN TERIMA KASIH}

"Penghargaan ditujukan kepada Dinas Perhubungan Sidoarjo, Badan Perencanaan dan Pembangunan Daerah Sidoarjo, Badan Pusat Statistik Sidoarjo, Kepala Desa Keboan Sikep dan Kepala Desa Ketajen yang telah memberikan banyak dukungan dan bantuan data data yang digunakan pada Penelitian ini

\section{DAFTAR PUSTAKA}

[1] A Manual on User Benefit Analysis of Highway and BusTransit Improvement" (1977) was published by the American Association of State Highway and Transportation Officials (AASHTO).

[2] Bina Marga, 1997, “Manual Kapasitas Jalan Indonesia (MKJI)", Yayasan Badan Penerbit Pekerjaan Umum, Jakarta.

[3] Bina Marga, 1992, "Standar Perencanaan Geometrik Untuk Jalan Perkotaan” Jakarta.

[4] Departemen Pekerjaan Umum 1977, “Tata Cara Pembebasan Tanah Untuk Kepentingan Pemerintah" Jakarta

[5] Kartika, A.A.G., 2006, “Ekonomi Jalan Raya” Diktat Kuliah, Program S-1 Jurusan Teknik Sipil FTSP Surabaya.

[6] Khristy,C. J. dan Lall, B. K., 2003, "Dasar-Dasar Rekayasa Trasnsportasi (Jilid 1, Edisi Ketiga)", Penerbit Erlangga, Jakarta.

[7] N.D Lea \& Associates LTD. (1975). “Road Improvement Project Draft Final Report", Republic of Indonesia Departemet Public Works And Electric Powes Di rectorate General of Highways.

[8] Oglesby, C.H. \& Hicks R.G. 1999 “Teknik Jalan Raya Edisi ke Empat jilid 1", Gramedia Jakarta. 